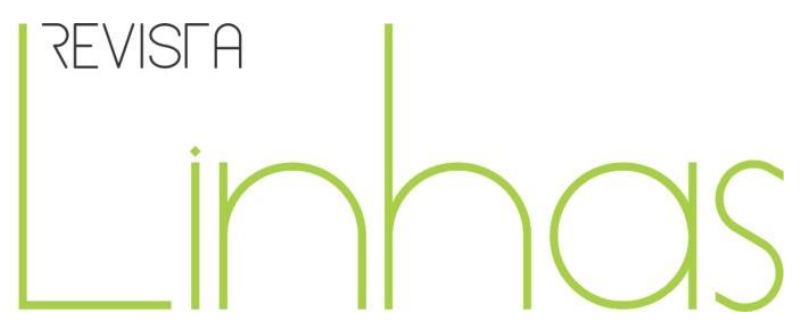

\title{
Relações construídas no diálogo e na mediação através do pensar: aprendizagem colaborativa na EAD
}

\begin{abstract}
Resumo
O presente artigo objetiva trazer para discussão a aprendizagem colaborativa evidenciada no espaço da EaD, no curso de Pedagogia da UFRGS, Universidade Aberta do Brasil, no polo do município de Vila Flores, Rio Grande do Sul. O estudo propõe uma reflexão interligada entre o Projeto Político Pedagógico do curso, a mediação entre as interdisciplinas do eixo $\mathrm{V}$, segundo pensamentos de Feuerstein (2014) e Freire (2015), que consolidam a práxis da aprendizagem colaborativa na docência on-line, ancorada por Montes (2016). Nesse contexto, evidenciamos a mediação da aprendizagem como prática colaborativa para a construção do conhecimento na docência, através da experiência do blog como uma estratégia de aprendizagem que possibilita desenvolver competências voltadas à reciprocidade, ao compartilhamento, ao desafio do desenvolvimento da curiosidade intelectual, ao significado e ao pertencimento entre os sujeitos envolvidos na construção da autonomia necessária para pensar a própria existência em relação ao outro, para uma educação mais humana.
\end{abstract}

Palavras-chave: Ensino a distância. Universidade Aberta do Brasil. Mediação. Aprendizagem colaborativa. Reflexão.

\author{
Valdete Gusberti Cortelini \\ Universidade de Caxias do Sul - UCS \\ - Caxias do Sul/RS - Brasil \\ valdetegusbertic@yahoo.com.br
}

Geraldo Antônio da Rosa

Universidade de Caxias do Sul - UCS

- Caxias do Sul/RS - Brasil garosa6@ucs.br

\section{Para citar este artigo:}

CORTELINI, Valdete Gusberti; ROSA, Geraldo Antônio da. Relações construídas no diálogo e na mediação através do pensar: aprendizagem colaborativa na EAD. Revista Linhas. Florianópolis, v. 21, n. 47, p. 385-404, set./dez. 2020.

\section{DOI: $10.5965 / 1984723821472020385$}

http://dx.doi.org/10.5965/1984723821472020385 


\title{
Relations built in the dialogue and mediation through thinking: collaborative learning in the Distance Education
}

\begin{abstract}
This article has the objective of bring for discussion the collaborative learning showed in the space of the Distance Education, in the course of pedagogy, of the Federal University of Rio Grande do Sul (UFRGS), Open University of Brazil, in the University Pole in the town of Vila Flores, on the Rio Grande do Sul. The study proposes an interconnected reflection between the Political Pedagogical Project of the course, the mediation between the interdisciplines from the $\mathrm{V}$ axis, following Feuerstein (2014) and Freire (2015), who consolidate the praxis of the collaborative learning in online teaching, based in Montes (2016). In this context, we highlight the mediation of learning as a collaborative practice for the construction of knowledge in teaching, through the experience of the blog as a learning strategy that makes it possible to develop skills aimed at reciprocity, sharing, the challenge of developing intellectual curiosity, the meaning and the belonging among the subjects involved in the construction of the necessary autonomy to think about their own existence in relation to the other, for a more human education.
\end{abstract}

Keywords: Distance Education. Open University of Brazil. Mediation. Collaborative learning. Reflection. 
Busca-se entender um pouco sobre o acontecimento da EaD no Brasil, através do advento da globalização, uma vez que as políticas brasileiras, no que se refere à economia, ao social e à educação, voltam-se para atender a propostas de um mercado mundial no qual, na maioria das vezes, o ensino tem valor mercadológico e não de democratização e emancipação. Vive-se a ambiguidade de uma educação de qualidade, socialmente referenciada, atualizada, mas que continua contribuindo para a exclusão social porque nem todos podem custear essas ofertas, já que se apresentam como produto (MAIA, 2003).

Em meio a tantas iniciativas para a institucionalização de uma cultura na formação a distância no Brasil, através de organizações que integram instituições de ensino superior, por meio de experiências de consórcios, merece destaque a iniciativa mais recente da Universidade Aberta do Brasil (UAB), em 2005. Esse sistema de ensino vem desmitificar a ideia de EaD como sinônimo de aligeiramento e falta de qualidade no ensino. Sua proposta, com as diferentes universidades credenciadas, traz padrões de qualidade e referenciais curriculares que norteiam o ensino no que se refere ao acesso, à democratização e à qualidade. No Decreto 5.800/2006 (BRASIL, 2006), fica instituída uma das maiores conquistas na modalidade do Ensino da Educação a Distância no Brasil: o Sistema Universidade Aberta, que, a princípio, foi coordenado pelo Ministério da Educação e, mais tarde, passa a ser avaliado e organizado pela CAPES.

O surgimento dos estudos a distância trouxe o conflito e a exigência para os espaços presenciais de repensarem sua maneira de organizar o processo de ensino e de aprendizagem. O desafio proposto fortaleceu as duas modalidades de ensino na busca de reflexões e avaliações em relação ao tempo, ao espaço e ao processo de construção do conhecimento.

Embora a EaD, em seu surgimento, tenha tido o propósito de formação de mão de obra, precisamos admitir que, para a época, foram iniciativas inovadoras e ousadas. Essa transição ocorrida inaugura um novo paradigma educacional, reforçado pela inserção das TIC (Tecnologias da Informação e Comunicação). Os recursos tecnológicos potencializaram a expansão da EaD que, através de seus ambientes virtuais, 
disponibilizou espaços de comunicação e acesso à informação, tornando prazeroso e atraente para o aluno esse novo conceito de aprender. Embora muitas vezes possa não parecer, esses espaços disponibilizam mecanismos que promovem a interação e a colaboração entre os envolvidos no processo de ensino e aprendizagem, dando suporte para que o sujeito desenvolva habilidades de autonomia e de criticidade.

O direcionamento para a nossa reflexão traz o recorte da dissertação desenvolvida no curso de Mestrado em Educação da Universidade de Caxias do Sul, com o tema Formação docente e os cursos de graduação em pedagogia na modalidade EaD: processos formativos e autonomia do sujeito, conforme nos propõe Paulo Freire em seu legado da "ação reflexão ação" num processo dialógico, e Reuven Feuerstein, por meio das experiências mediadas da aprendizagem, tendo como princípio o ato permanente do pensar. É fundamental discorrermos acerca do problema de pesquisa, cujo objetivo foi identificar quais as estratégias de mediação na formação de professores de pedagogia, na modalidade em EaD, podem potencializar a construção da aprendizagem e de um sujeito autônomo no processo de estruturação da docência. As análises apresentadas foram ancoradas, também, na contribuição de outros autores que fundamentaram a ideia de sujeitos protagonistas de uma formação docente com autonomia.

A presente pesquisa direcionou-se para o estudo de campo através da observação de um semestre do desenvolvimento das aulas do curso de Pedagogia na modalidade EaD, Universidade Aberta do Brasil na Serra Gaúcha, pela UFRGS. O currículo organiza-se em torno de eixos temáticos que articulam em cada semestre os conhecimentos específicos, teóricos e práticos. Os eixos contemplam as interdisciplinas e os seminários integradores. A observação centra-se na matriz curricular do eixo V, do Projeto Político Pedagógico do referido curso.

Observamos que os pressupostos teóricos se fundamentam na autonomia, na relação entre a prática pedagógica e a pesquisa, buscando a articulação dos componentes curriculares de forma compartilhada e interdisciplinar, assim como um diálogo permanente entre teoria e prática. O curso, além de articular os componentes curriculares, faz conexões dos mesmos com as experiências dos docentes nas suas práticas pedagógicas. 
Estudos já realizados por Morés (2014, p. 372), de análise do Projeto Pedagógico da UFRGS, confirmam as observações citadas ao afirmar que

O currículo tangencia a inovação, estando organizado em eixos temáticos que agregam e articulam, em cada semestre, os conhecimentos específicos, teóricos e práticos. Os eixos são propostos por interdisciplinas (grandes áreas que congregam conhecimentos específicos) e Seminário Integrador. Essa proposta curricular do curso se propõe a superar a dicotomia proporcionada pelos modelos convencionais de cursos que, tradicionalmente, apenas teorizam sobre a prática, sem agregar-lhe inovações. Frente a essa superação, o currículo apresenta características interdisciplinares agregando e articulando conhecimentos específicos, teóricos e práticos em cada semestre, conforme e expresso no Projeto Pedagógico. (UFRGS et al., 2006)

Tanto no campo da observação quanto no das análises, é possível trazer reflexões sobre a dinâmica do blog no desenvolvimento das aulas, pois é realizado de forma colaborativa pelas alunas, com a intervenção do tutor e do professor. Freire (1981, p. 82) nos faz pensar que "a consciência crítica não se constitui através de um trabalho intelectualista, mas na práxis - ação e reflexão".

Entendemos que as investigações e construções teóricas precisam avançar o plano do intelecto, pois é na prática que se confirmam, são analisadas e legitimadas.

\section{Aprendizagem colaborativa através da mediação}

Nessa perspectiva, somos desafiados a compreender que a aprendizagem se constrói através das relações mediadas pelo ato da reflexão, pois permite identificar estágios de desenvolvimento de nosso processo formativo a caminho da autonomia necessária. Desse modo, quem está na posição de educador tem condições de desafiar, questionar e possibilitar diferentes situações de mediação entre os conhecimentos existentes e os conhecimentos construídos, podendo atender às necessidades do sujeito mediado, inserido na dinâmica social da atualidade.

Montes (2016) nos traz a ideia de aprendizagem colaborativa apoiada nos seguintes autores: 
Stahl (1996) define a aprendizagem colaborativa com suporte computacional como uma área das ciências da aprendizagem que estuda como as pessoas aprendem em grupo e mediadas por computador. Ainda afirma que é um processo por meio do qual indivíduos negociam e compartilham entendimentos relevantes à resolução do problema posto. (STAHL 1996, apud MONTES, 2016, p. 51)

Podemos identificar que a EaD teve inúmeros avanços tecnológicos, fazendo com que mais sujeitos procurassem essa modalidade de ensino para aperfeiçoar seus conhecimentos. O grande desafio está justamente na forma como esse conhecimento se relaciona e se projeta entre os sujeitos e os contextos envolvidos. Observa-se a ruptura de uma educação que simplesmente atende às necessidades econômicas. Estamos diante de um novo sujeito, que reconhece o seu entorno, aproximando-o de sua identidade subjetiva. Dessa forma, compreende-se a aprendizagem colaborativa na dinâmica das relações e da ação do pensar. É possível compreender o sujeito na extensão com o conhecimento, o seu contexto e a sua existência.

Para Behrens (1999), a aprendizagem colaborativa se assenta sobre os quatro pilares destacados por Jacques Delors. 1. Aprender a conhecer relacionado ao prazer em descobrir, ter curiosidade; 2 . Aprender a fazer habilidades do trabalho em grupo; 3. Aprender a viver juntos capacidade de compreender o outro; 4. Aprender a ser - baseado nas novas exigências sociais. (BEHRENS, 1999, apud MONTES, 2016, p.52)

Embora sejam usadas formas diferentes para conceituar a aprendizagem colaborativa, é possível identificar que a marca central se define como a construção do conhecimento e das competências necessárias através das relações estabelecidas no grupo a partir do cotidiano vivenciado. A dinâmica de aprendizagem construída através do blog, nas aulas do curso de Pedagogia observado, traz como parâmetro a construção coletiva, com o objetivo de socializar experiências da prática escolar, interligadas com o referencial teórico trabalhado e conectadas com as percepções, as críticas, as construções e as inferências do grupo, sempre mediadas pelo professor e pelo tutor. 
A turma de Pedagogia EaD é composta por alunas que já estão exercendo a docência e trazem para a discussão a prática da sala de aula. O momento observado nos oportunizou, através de relatos e explicações dos professores e algumas intervenções dos tutores, identificar a importância das relações mediadas na construção da aprendizagem, nas quais,

O professor, na condição de mediador, assume o compromisso não só de socializar a informação, como de disponibilizar os processos cognitivos socialmente produzidos. Ao identificar os processos inerentes à conduta intelectual, e decorrente do conteúdo estudado, raciocina com o aluno e com ele aprende. (ZANATTA DA ROS, 2002, p. 38)

Essa ideia pode muito bem ser compreendida na prática observada das alunas, nas postagens no blog sobre as etapas de desenvolvimento do projeto de aprendizagem desenvolvido com suas turmas nas escolas onde atuam. O aluno participa na condição de expor a sua ideia e de refletir sobre outra ideia posta, acrescentando informações, reforçando suas convicções ou, até mesmo, discordando das colocações realizadas. Em tal contexto, aprende-se a respeitar o outro, a ser crítico e a construir competências.

Conforme Feuerstein, Feuerstein e Falik (2014), quando registramos e documentamos nossa prática, atribuímos significado para a nossa escrita, compartilhamos nosso aprendizado e agregamos os conhecimentos construídos com os saberes prévios. No momento em que recebemos uma intervenção de outra pessoa sobre nossas produções, necessitamos contar com autorregulação diante de novas posturas e concepções. Somos desafiados a desconstruir nossos conceitos e, por meio do compartilhamento e da reflexão de ideais, somos provocados a ampliar nosso campo mental. Nessa relação entre mediador e mediado, ocorrem as transformações do processo de aprendizagem e nos tornamos pertencentes aos saberes construídos.

Essa dinâmica proposta pelo blog nas aulas do curso de pedagogia permite que os registros não sejam apenas meros relatos descritivos, mas que promovam o pensar permanente no saber específico e que, cada aluna, na práxis do seu dia a dia, esteja interrelacionada com as experiências do grupo. O professor, no papel de mediador, é um observador dos momentos em que se faz necessário mediar a aprendizagem através do 
desafio do pensar. O mediado é desafiado a pensar continuamente sobre a sua prática vinculada às experiências dos alunos e embasadas nos teóricos estudados.

O mediador humano não se impõe continuamente ou constantemente sobre a pessoa que está sendo mediada e o mundo. Ele não cobre todo o território entre eles, mas deixa para o mediado uma grande área de exposição direta ao estímulo. Mas na área em que o agente mediador está ativo de diversas formas. Um exemplo é a modificação significativa do estímulo e uma exposição focada para mediar de forma intencional e controlada. Portanto, o mediador entrega para o mediado componentes que serão responsáveis por sua habilidade de entender fenômenos, procurar entre eles associações e conexões, e assim se beneficiar deles e ser modificado. (FEUERSTEIN; FEUERSTEIN; FALIK, 2014, p. 64-65)

Esse movimento permanente do sujeito na construção do saber, sentindo-se parte do processo e responsável pelas construções cognitivas a partir de suas reflexões e da interação com o outro, possibilita pensar "a ação" continuamente, e o pensar é o motor das transformações educacionais. Tais momentos são disponibilizados quando o professor entende que

[...] o fundamental é que o professor e alunos saibam que a postura deles, do professor e dos alunos, é dialógica, aberta, curiosa, indagadora e não apassivada, enquanto fala ou enquanto ouve. O que importa é que professor e alunos se assumam epistemologicamente curiosos. (FREIRE, 2015, p. 83)

Sendo assim, torna-se claro que a mediação acontece somente quando são disponibilizados momentos de interação por meio do diálogo, sejam eles na forma de debates on-line ou presenciais, possibilitando que o mediado modifique as estruturas mentais, evoluindo seus saberes e sua maneira de interagir com o outro, visando à sua autonomia no pensar. Freire nos alerta que a autonomia se constrói em ambientes sóciohistóricos livres da opressão e capazes de transpor a ação educativa baseada no respeito e na dignidade humana. A autonomia na educação moderna assume relevante importância no sentido social, político e pedagógico. Não basta apenas desenvolver a 
autonomia no ser humano: é preciso, principalmente, conquistar a libertação das opressões das estruturas da sociedade.

Os oprimidos, que introjetam a "sombra" dos opressores e seguem suas pautas, temem a liberdade, na medida em que esta, implicando a expulsão desta sobra, exigiria deles que "preenchessem" o "vazio" deixado pela expulsão com outro "conteúdo" - o de sua autonomia. O de sua responsabilidade, sem o que não seriam livres. A liberdade, que é uma conquista, e não uma doação, exige uma permanente busca. (FREIRE, 2016, p. 68, grifo do autor)

Essa busca, proposta por Freire, nos faz pensar sobre o quanto precisamos estar vigilantes no entendimento de liberdade como responsabilidade e não como doação. Esse movimento, uma vez internalizado, passa a ser processo, por meio das relações entre pensamento e linguagem, que são inacabadas.

Nessa vigilância proposta por Freire, é necessário perceber que os aspectos culturais apresentam questões preponderantes na construção de um sujeito autônomo e reflexivo. Para compreender melhor as estruturas histórico-sociais que fundamentam a ideologia da sociedade, é necessário entender as relações de poder existentes na ideologia educacional que, ao mesmo tempo em que apresenta políticas de uma educação que promove a autonomia, estabelece um controle coletivo da mesma. Trata-se de uma autonomia controlada: “Ademais, as organizações humanitárias se dirigem sempre e apenas à vida nua, e nunca problematizam, politicamente, a proliferação desta mesma vida nua da qual se alimentam" (DUARTE, 2008, p. 12).

São os perigos que a atual sociedade democrática nos estabelece, segundo Agamben (2017), que determinam quais os direitos humanos "assegurados", quem são os excluídos e os incluídos, os dentro da lei e os fora da lei. Devemos estar atentos às decisões do soberano, analisando suas ações na ótica da vida versus política, com enfoque na existência humana.

Podemos dizer que o pensar é considerado, hoje, uma grande ameaça para a ideologia e o poder em vigência, pois, quanto menos tempo for oportunizado para que o sujeito pratique a ação do pensar, maior a facilidade de manipulação desse indivíduo. A reflexão, para ter eficácia, precisa ser promovida no ambiente escolar que, por sua vez, 
apresenta horários fechados e carga de trabalho exaustiva que afasta o docente desse exercício vital. Além disso, as cobranças de vencer conteúdos informativos para obter resultados com avaliações externas direcionam o trabalho do professor para, única e exclusivamente, repassar conteúdos e conhecimentos impostos.

Minha presença de professor, que não pode passar despercebida dos alunos na classe e na escola, é uma presença em si política. Enquanto presença não posso ser uma omissão, mas um sujeito de opções. Devo revelar aos alunos a minha capacidade de analisar, de comparar, de avaliar, de decidir, de optar, de romper. Minha capacidade de fazer justiça, de não falhar à verdade. Ético, por isso mesmo, tem que ser o meu testemunho. (FREIRE, 2015, p. 96)

Diante do exposto e embasado nos princípios de Paulo Freire, identificamo-nos com uma educação compreendida na relação entre professor, aluno e processo de aprendizagem que, também na modalidade EaD, pressupõe-se que desenvolva os mecanismos necessários para uma relação entre aluno e professor, ambos responsáveis por construir o conhecimento voltado ao compromisso "cidadão de autonomia" e “emancipação do sujeito”. A EaD, nesse cenário, propõe-se a estabelecer trocas e relações significativas que, além de darem condições de o sujeito construir sua autonomia no saber, possam despertar e fomentar a busca contínua dos saberes necessários para que viva com dignidade e tenha seus direitos respeitados.

Não é possível pensar os seres humanos longe, sequer, da ética, quanto mais fora dela. Estar longe ou pior, fora da ética, entre nós, mulheres e homens, é uma transgressão. É por isso que transformar a experiência educativa em puro treinamento técnico é amesquinhar o que há de fundamentalmente humano: o seu caráter formador. (FREIRE, 2015, p. 34)

O ser humano não pode apresentar um testemunho ético se não conseguir se sentir em um processo de construção permanente do "seu” ser humano livre, porém responsável pelo outro e, assim, estabelecendo autonomia entre ambos. Essa liberdade individual, conquistada no coletivo, inaugura a emancipação compreendida na vivência 
entre seres humanos da mesma espécie com personalidades e características diferentes, mas regidos pelas leis da ética.

Trazer a ação pedagógica para a reflexão é uma construção ética da docência, e esse caminho se concretiza por meio de processo contínuo de construir e reconstruir aprendizagens que tenham significado e possibilitem o ensinar e o aprender com dignidade.

Segundo Morés (2014, p. 369), "acredita-se que a inovação não significa apenas a produção de um produto novo, mas também, de um processo de mudança e de ressignificação em determinado contexto". Esses princípios, embasados na reflexão, com o passar do tempo são aprimorados, mas a caminhada de base sempre fará parte do todo. Não se avança na qualidade do ensino sem levar em consideração o primeiro passo. Somos uma continuidade no processo que se constitui na ação-reflexão-ação.

Por isso é que, na formação permanente dos professores, o momento fundamental é o da reflexão crítica sobre a prática. É pensando criticamente a prática de hoje ou a de ontem que se pode melhorar a próxima prática. $\mathrm{O}$ próprio discurso teórico, necessitando à reflexão crítica, tem de ser de tal modo concreto que quase se confunda com a prática. O seu "distanciamento" epistemológico da prática enquanto objeto de sua análise, deve ela "aproximá-lo" ao máximo. Quanto melhor faça esta operação tanto mais inteligência ganha da prática em análise e maior comunicabilidade exerce em torno da superação da ingenuidade pela rigorosidade [...]. (FREIRE, 2015, p. 40)

Observa-se que o Projeto Político Pedagógico apresenta a preocupação de oferecer o curso de Pedagogia na modalidade EaD, garantindo a sustentação legal e pedagógica comprometida com a qualidade na formação de professores.

A perspectiva da formação docente especializada para a modalidade da EaD exige uma reflexão sobre um "novo pensar" dos participantes, de forma ativa e crítica, bem como os seus instrumentos didáticos, práticas e projetos pedagógicos. Com tantas possibilidades de escolha, o docente precisa buscar e trocar experiências, de modo a construir referenciais que orientem suas escolhas, para atingirem seus objetivos pedagógicos no contexto de sua prática educativa dinâmica e contínua, podendo ser alterada pelas respostas tecnológicas e das práticas educativas que surgirão no decorrer do processo de ensino-aprendizagem. (DEMARCO; HONORATO, 2013, p. 212) 
As ideias centrais dessas estratégias trazem, nos escritos desse documento, confirmações dos fundamentos das teorias mencionadas, ou seja, apresentam o norte do ensino voltado ao conhecimento construído nas relações entre mediador e mediado, compreendendo os sujeitos inseridos numa dinâmica social que, por meio da ação e reflexão deste espaço, desenvolvem competências responsáveis por construir a autonomia necessária na busca constante de transformações.

Assim como o PPP apresenta os princípios norteadores da concepção do conhecimento, traz também os princípios fundamentais a serem articulados pedagogicamente para que essa concepção seja construída na prática da sala de aula. Apresenta-nos indicadores de como as estratégias de mediação são concebidas no universo educacional do curso, compreendendo-as em uma espécie de rede em que conhecimento, contexto, sujeitos e práticas se entrelaçam na construção dos saberes.

Além da concepção de conhecimento e das estratégias para que ele aconteça na dinâmica educacional, o documento apresenta os possíveis resultados esperados diante do processo educativo construído ao longo dos anos do desenvolvimento do curso. Embora se tenha consciência de que o processo é único e marcado pelas interações entre sujeitos, com o referencial teórico e com as práticas, a articulação na dinâmica do curso prevê o desenvolvimento do sujeito preparado para atuar nas especificidades que o curso direciona à sua formação para o mundo do trabalho.

O PPP estrutura-se em eixos nos quais estão dispostas as disciplinas, interdisciplinas e seminários integradores, identificando a presença das articulações projetadas e os processos de mediação da aprendizagem dos princípios norteadores do referido curso. A mediação deve encorajar o mediado a prestar atenção a vários estímulos, considerar todos os fatos relevantes e compreender que as coisas não podem ser vistas como entidades isoladas (SOUZA, 2003, p. 83).

Paralelamente à Matriz Curricular obrigatória do curso, são oferecidas atividades complementares, nas quais os professores do curso são provocados a oferecer diferentes situações de pesquisa e extensão ao longo do seu percurso.

É justamente nas mudanças da forma de tratar o ensino e a aprendizagem que a dinâmica da existência humana vai se construindo de forma inteligente, segundo 
Feuerstein, modificando as estruturas já construídas, permitindo novas estruturas que se adaptam a novos estímulos.

Se analisarmos o dia a dia da prática pedagógica, identificaremos concepções de ensino tradicionais, evidenciando que as concepções dialógicas, que estabelecem relações e possibilitam a construção do conhecimento, ainda não foram internalizadas pelos docentes e transpostas para as suas práticas. "Ao falar da construção do conhecimento criticando a sua extensão, já devo estar resolvido nela, e nela, a construção estar envolvendo os alunos" (FREIRE, 2015, p. 47-48, grifo do autor).

Talvez, quando conseguirmos compreender que o ser humano é inacabado, trataremos o conhecimento como algo em constante mudança, que não pode ser concebido como uma verdade absoluta nem como o professor sendo o único detentor do saber, mas um mediador, possibilitando as relações entre os saberes do docente e do aluno. É importante, inclusive, que consigam desacomodar seus esquemas mentais e reorganizar seus conhecimentos, cada um no seu nível de reflexão, permitindo que professor e aluno sejam indivíduos que ensinem e aprendam através de um diálogo permanente que contribua para a emancipação dos sujeitos. Para tais objetivos serem atingidos, é necessário buscarmos estratégias que possam mediar, através do diálogo construído por meio de uma aprendizagem colaborativa, o pensar e a constituição de sujeitos autônomos e comprometidos com um mundo mais humano.

\section{O pensar como um desafio para a construção do sujeito autônomo por meio da mediação}

Sustentados pelos princípios de Paulo Freire e Feuerstein, podemos destacar algumas categorias que são comuns e essenciais para que a aprendizagem colaborativa aconteça. Ambos os autores apostam em uma aprendizagem construída na coletividade, através do diálogo, do aprender a aprender e a pensar, voltada para o desenvolvimento ético. Uma autonomia responsável, construída por meio de uma educação reflexiva e problematizadora, voltada à essência do ser. A EaD, nesse cenário, propõe-se a estabelecer trocas e relações significativas que, além de darem condições de o sujeito 
construir sua autonomia no saber, possam despertar e fomentar a busca contínua dos saberes necessários para que viva com dignidade e tenha seus direitos respeitados.

Dessa forma, quando a educação se abre para o diálogo, acontece a interação entre os meios de comunicação e as características dos alunos e dos conteúdos trabalhados, podendo avaliar, assim, programas de EaD pelo grau de autonomia que proporcionam para o aluno na construção do saber. "Minha presença no mundo não é a de quem a ele se adapta, mas a de quem nele se insere. É a posição de quem luta para não ser apenas objeto, mas sujeito também da História" (FREIRE, 2015, p. 53, grifo do autor).

Parece-nos que um dos problemas que enfrentamos na educação é o de analisarmos os aspectos que compõem a sua estrutura de forma compartimentada e superficial. A todo momento somos convidados, de maneira direcionada ou não, a cooperamos de forma colaborativa ou tensionada para as relações de poder que permeiam as estruturas organizacionais da sociedade. Não podemos entender a educação e qualquer mudança nela inaugurada sem identificar claramente a sua relação com a história, a economia e a política.

Entrelaçada por essa macroestrutura, forma laços de poder que defendem interesses de acordo com a época em que vivemos. Muito se fala, hoje, em direitos humanos, igualdade de oportunidades e sujeitos construtores da própria história, mas, se analisarmos as relações de poder existentes na sociedade, caminhamos para reforçar o sistema capitalista em detrimento da emancipação do ser humano.

Paulo Freire, quando nos faz pensar sobre os saberes fundamentais para a prática docente, permite-nos refletir sobre como agimos diante da diversidade e do diferente. "Faz parte igualmente do pensar certo a rejeição mais decidida a qualquer forma de discriminação. A prática preconceituosa de raça, de classe, de gênero ofende a substantividade do ser humano e nega radicalmente a democracia" (FREIRE, 2015, p. 37).

Podemos identificar no curso de Pedagogia da UFRGS, modalidade EaD, UAB, que diferentes estratégias são utilizadas para mediar o conhecimento através dos diferentes momentos organizados para atender às necessidades do período atual. É na diversidade que se constrói qualidade e riqueza de experiências. O blog, construído com os relatos individuais e compartilhados com as vivências do grupo, faz com que a aprendizagem seja 
elaborada de forma colaborativa e mediada pelo professor com o propósito de alcançar os seus objetivos. Possibilita, também, que cada sujeito modifique suas estruturas mentais no campo individual e no contexto do grupo.

A interatividade faz com que a prática pedagógica seja pensada e repensada, assim, atribuindo significado às informações e ao conhecimento, sendo possível compreender o sujeito inserido num contexto e, por meio de modificações, propõe-se a torná-lo mais humano e comprometido com o outro. O indivíduo, desacomodado pelas mediações entre os sujeitos e o meio, modifica suas estruturas mentais na busca do equilíbrio, pois no contato com novas relações passa por novas mudanças, sempre buscando resolver as situações de conflito com o mundo. É o ser humano em constante modificabilidade. Segundo Souza (2003, p. 30), Feuerstein nos diz que "A modificabilidade estrutural cognitiva é a parte nuclear desse processo de educabilidade, pois uma mudança estrutural perpetua a mudança no sistema cognitivo”.

Considera-se, portanto, fundamental analisarmos a aprendizagem construída nas vivências e nas interações entre os sujeitos nas suas individualidades e no coletivo durante o trabalho pedagógico, preocupando-se com o desenvolvimento afetivo e cognitivo, compreendendo o sujeito em sua realidade social, histórica e cultural.

O mediador, no processo pedagógico que vislumbra a modificabilidade estrutural do sujeito, precisa estar constantemente alerta para as intervenções realizadas e ter claro que somente será permitida a criação de um espaço comum se as ações compartilhadas com sentimentos, discussões e embasamento teórico possibilitarem avançar para novas etapas e se a comunicação for capaz de transformar essa modificabilidade, caso contrário, a cristalização e a estagnação far-se-ão presentes. É essencial que o mediador possa traçar seu caminho de forma intencional, sem espaço para neutralidade.

Segundo Feuerstein, a proposta de trabalho pedagógico destaca o vir a ser, que pressupõe a inclinação do sujeito para a transformação. Essas mudanças são dinâmicas. $O$ sujeito modifica-se e torna-se responsável por transformar o seu entorno. Diante das ideias expostas, torna-se pertinente falar sobre o compromisso da educação: ou se compromete na promoção do pensar por meio das relações, ou se compactua com as ideias de uma ideologia dominante. De que lado você está? 


\section{Considerações finais}

Atualmente, ainda há muito preconceito em relação à EaD, porém, foi possível constatar, através do exposto, que nessa modalidade de ensino não deixam de acontecer as relações, a ajuda mútua, o desenvolvimento individual e coletivo, as trocas. Além disso, os recursos tecnológicos trouxeram facilidades na construção dos debates e das discussões. Traz a possibilidade, também, de que se atinja uma maior parte da população para dar continuidade aos estudos, tendo em vista que um de seus princípios é o respeito aos tempos e espaços que o sujeito disponibiliza para dar continuidade à sua formação.

Por se tratar de um curso para professores, uns realizando a primeira graduação e a grande maioria buscando uma segunda formação, a administração do tempo é essencial para serem possíveis esses momentos de aperfeiçoamento. O curso, por constituir-se de momentos presenciais e outros a distância, permite estabelecer o vínculo necessário pela presença do outro, e, a partir dele, em momentos a distância, organizarem-se nas discussões, nos trabalhos e nos projetos.

Compreender a dinâmica do curso fez com que se quebrassem alguns paradigmas e preconceitos formados em relação à EaD. A possibilidade de conviver um semestre com o grupo, entendendo como as discussões e os encaminhamentos para a construção dos conhecimentos necessários para cada disciplina foram direcionados, trouxe-nos a visão de que não podemos mais pensar em uma educação que não leve em consideração as necessidades dos alunos. A inevitabilidade de compreender que podemos aprender em tempos e locais diferentes vem confirmar que as estruturas formais de ensino precisam sofrer modificações.

Essas afirmações não dispensam o trabalho do professor e muito menos trazem o conhecimento com valor mercadológico. Acreditamos que a tecnologia trouxe algumas mudanças muito significativas que, somadas aos projetos educacionais de qualidade que já estão sendo desenvolvidos, darão o salto qualitativo de que tanto falamos na educação.

Como já mencionamos anteriormente, a Universidade Federal do Rio Grande do Sul, credenciada na UAB, com o curso de Pedagogia, tem um diferencial em seu trabalho: sua proposta de ensino apresenta qualidade e preocupação com a formação do sujeito 
pensante e, assim, desenvolve-se de forma autônoma em relação às suas ações, ao seu pensar e na relação com o outro. A ação contínua do pensar constrói no sujeito a autonomia de ser responsável e ético consigo mesmo e com o outro.

Uma educação que prioriza o pensar de acordo com a realidade e o contexto vivido, que discute seus avanços, permitindo que os seus princípios norteadores sejam estabelecidos coletivamente e regados continuamente pelo ato de avaliar, compreendendo o sujeito como um ser inacabado e em constante modificabilidade na construção do seu conhecimento individual e coletivo, desenvolve seu ensino no qual mediador e mediado, inseridos nesse contexto de desafios, construam-se responsavelmente enquanto indivíduos, para que coletivamente suas ações os humanizem. Essa postura constrói-se gradativamente pela ação do pensar e, por meio da reflexão, constitui-se em autonomia e ética. Nesse parâmetro de pensamento, somos responsáveis uns pelos outros da mesma forma que nos responsabilizamos pelo mundo. Assim, também, humanizamo-nos.

Mediante o percurso realizado, é importante e necessário retornar ao ponto de partida desta pesquisa. Ao definirmos o seu tema e o problema, foram traçados objetivos com o propósito de encontrar possíveis respostas diante dos mesmos. Durante o percurso da pesquisa, foi possível fazer uma retrospectiva dos avanços da EaD no Brasil, marcada pela conquista da UAB e identificada como uma política de responsabilidade e de qualidade nessa modalidade de ensino.

Atendendo ao tema de identificar as marcas de um sujeito autônomo, no processo formativo de estruturação da docência, nos cursos de graduação em Pedagogia EaD, trouxemos o referencial teórico do educador Paulo Freire com ênfase na sua teoria sobre a pedagogia da autonomia, e do psicólogo e educador Reuven Feuerstein, na concepção da experiência de aprendizagem mediada, na construção do conhecimento responsável por modificar as estruturas mentais responsáveis pelas transformações no contexto em que o sujeito está inserido. Ambos trazem como princípio o ato permanente do pensar. Ancorando-se na pesquisa sobre a estruturação da UAB e no referencial teórico proposto por Freire e Feuerstein, foi possível realizar a análise do PPP do curso de Pedagogia, na modalidade EaD, da UFRGS, que é o documento norteador dessa modalidade de ensino. 
Avançando na pesquisa de campo, a UFRGS nos oportunizou que realizássemos as observações das aulas presenciais e do ambiente virtual compreendendo o estudo das disciplinas do eixo $V$ do curso. Esse espaço de análises, aliado ao questionário respondido por todas as alunas e ancorado com o referencial teórico apresentado no decorrer da pesquisa, colocou-nos diante de possíveis respostas ao problema de pesquisa que nos desafiou a buscar as estratégias de mediação na formação de professores de pedagogia na modalidade EaD que potencializam a construção da aprendizagem e de um sujeito autônomo no processo de estruturação da docência.

Queremos destacar que os pressupostos teóricos apresentados no PPP do curso fundamentam-se na autonomia, na relação entre a prática pedagógica e a pesquisa, buscando a articulação dos componentes curriculares de forma compartilhada e interdisciplinar, propondo um diálogo permanente entre teoria e prática. O curso, através do semestre observado, possibilitou a mediação entre o currículo e as experiências docentes trazidas pelas alunas, de suas práticas pedagógicas de acordo com o seu contexto educacional.

Nessa perspectiva, somos desafiados a compreender que a aprendizagem se constrói através das relações mediadas pelo ato da reflexão, pois permite identificar estágios de desenvolvimento de nosso processo formativo a caminho da autonomia necessária para que, estando na posição de educador, tenhamos condições de desafiar, questionar e possibilitar diferentes situações de mediação entre os conhecimentos existentes e os conhecimentos construídos, podendo atender às necessidades do sujeito mediado, inserido na dinâmica social da atualidade.

Paralelamente ao blog, as alunas participaram de fóruns on-line de discussão que, também de forma colaborativa, aprofundaram mais as ideias, apresentando as construções da aprendizagem provenientes dos registros reflexivos realizados no blog. Esse exercício de síntese das aprendizagens construídas e interligadas com a teoria dão a sustentação necessária para compreendê-las no fundamento da sua existência. Além disso, auxiliam os alunos na estruturação e apresentação do workshop de avaliação realizado no final do período que compreende o estudo de um eixo das interdisciplinas. Nesse momento, entende-se que o processo de aprendizagem acontece na coletividade, mas sua estruturação mental acontece de forma individual. As construções e inter- 
relações estabelecidas entre os conhecimentos teóricos do eixo com a prática pedagógica constituem o docente na condição de sujeito inacabado.

Esse movimento permanente do sujeito na construção do saber, sentindo-se parte do processo e responsável pelas construções cognitivas a partir de suas reflexões e da interação com o outro, possibilita pensar "a ação" continuamente, e o pensar é o motor das transformações educacionais. Portanto, torna-se claro que a mediação acontece somente quando são disponibilizados momentos de interação através do diálogo, sejam eles na forma de debates on-line ou presenciais, possibilitando ao mediado modificar as estruturas mentais, evoluindo nos seus saberes e na sua maneira de interagir com o outro, visando à sua autonomia no pensar.

\section{Referências}

AGAMBEN, Giorgio. Mediossinfin: notas sobre la política. Buenos Aires: Adriana Hidalgo Editora, 2017.

BRASIL. Decreto n. 5.800, de 8 de junho de 2006. Dispõe sobre o Sistema Universidade Aberta do Brasil - UAB. Brasília: Presidência da República, 2006. Disponível em: http://www.planalto.gov.br/ccivil_03/_Ato2004-2006/2006/Decreto/D5800.htm. Acesso em: 18 mar. 2018.

DEMARCO, Silvia R. S.; HONORATO, Hercules G. A educação a distância e a tutoria: alguns olhares. In: V SEMINÁRIO INTERNACIONAL DE EDUCAÇÃO A DISTÂNCIA. Belo Horizonte, 2013. Anais. Belo Horizonte: UFMG, 2013, p. 206-2016. Disponível em: https://livrozilla.com/doc/1244489/trabalho-docente-na-ead---universidade-federal-deminas. Acesso em: 18 mar. 2018.

DUARTE, Andre. Sobre a biopolítica: de Foucault ao século XXI. Revista Cinética, Curitiba, v. 1, p. 1-16, 2008. Disponível em: http://docplayer.com.br/37603058-Sobre-a-biopoliticade-foucault-ao-seculo-xxi.html. Acesso em: 26 ago. 2017.

FEUERSTEIN, Reuven; FEUERSTEIN, Refael S.; FALIK, Louis H. Além da Inteligência: aprendizagem mediada e a capacidade de mudança do cérebro. Petrópolis: Vozes, 2014.

FREIRE, Paulo. Ação cultural para a liberdade. 5. ed. Rio de Janeiro: Paz e Terra, 1981. 
FREIRE, Paulo. Pedagogia da autonomia: saberes necessários à prática educativa. 52. ed. Rio de Janeiro: Paz e Terra, 2015.

FREIRE, Paulo. Pedagogia do oprimido. 60. ed. Rio de Janeiro: Paz e Terra, 2016.

MAIA, Marta de Campos. Educação a distância e o ensino superior no Brasil. Revista Brasileira de Aprendizagem Aberta e a Distância, São Paulo, v. 2, p. 1-19, dez. 2003.

MONTES, Marta Teixeira do Amaral. Aprendizagem colaborativa e docência online. Curitiba: Appris, 2016.

MORÉS, Andréia. Cursos de pedagogia EaD: superando desafios - construindo inovações. Revista Educação, Santa Maria. v. 39, n. 21, p. 367-378, maio/ago. 2014. Disponível em: http://docplayer.com.br/20398493-Cursos-de-pedagogia-ead-superando-desafiosconstruindo-inovacoes.html. Acesso em: 18 maio 2017.

SOUZA, Ana Maria Martins de. A mediação como princípio educacional: bases teóricas das abordagens de Reuven Feuersetein. São Paulo: Editora Senac, 2003.

UFRGS. UFSC. REDISUL. MEC. SEED. Projeto EaD curso de licenciatura em pedagogia: anos iniciais do ensino fundamental. Porto Alegre, 2006. Disponível em: http://www.ufrgs.br/pead2014/documentos-do-curso/projeto-pedagogico-do-curso. Acesso em: 12 mar. 2017.

ZANATTA DA ROS, Silvia. Pedagogia e mediação em Reuven Feuerstein: o processo de mudança em adultos com história de deficiência. São Paulo: Plexus Editora, 2002.

Recebido em: 21/10/2018 Revisões requeridas em: 05/01/2019 Aprovado em: 31/08/2020

Universidade do Estado de Santa Catarina - UDESC

Programa de Pós-Graduação em Educação - PPGE

Revista Linhas

Volume 21 - Número 47 - Ano 2020 revistalinhas@gmail.com 